\title{
Upstream Flow Characteristics Influenced by Gap Backwater in Wide and Narrow Alternated Channels in Mountainous Areas
}

\author{
Hu Lin \\ College of Water Conservancy and Hydropower \\ Engineering \\ Sichuan Agriculture University \\ Ya an, Peoples R China \\ e-mail:HuLin_sicau@163.com \\ Shuting Miao \\ College of Water Conservancy and Hydropower \\ Engineering \\ Sichuan Agriculture University \\ Ya an, Peoples R China \\ e-mail: HuLin_sicau@163.com
}

\author{
Yun Zeng* \\ College of Water Conservancy and Hydropower \\ Engineering \\ Sichuan Agriculture University \\ Ya an, Peoples R China \\ e-mail: zengyun@sicau.edu.cn(corresponding author)
}

\begin{abstract}
This paper chooses the wide and narrow alternated channel in upstream of Baoxing River as the research object, establishes a three-dimensional flow calculation model and studies the effects of gap backwater on flow characteristics of the water in upstream channel under different conditions. The results show that there is backflow along both sides of the mainstream in upstream of gap because of the water-resistance effects of gap. With the increase of flow rate, backflow presses the mainstream, so that cross-sectional velocity distribution in wide section becomes more uniform; at the section not affected by the backwater, as the flow increases, the bed shear stress increases, and the peak is distributed in the middle of the channel region; when the flow rate further increases, under the effect of the backflow and the backwater, the bed shear stress at the middle region of wide section tends to decrease first and then increase. And velocity and bed shear stress distribution in the cross section has significant peaks within a certain flow range.
\end{abstract}

Key words -wide and narrow alternated channel; backwater; Velocity distribution; bed shear stress; three dimensional flow field

\section{THE PRESENT SITUATION OF THE CHANNEL}

The mountain streams are affected by geological conditions and riverbed evolution, and the structure and lithology are inconsistent where the river flows through. So areas with low resistance to erosion and syncline often become gully, while areas with hard rock and Anticline become narrow. Upstream of Baoxing River has formed multiple wide and narrow alternated channels, due to the difference of flow capacity between Wide section and Narrow section, causing severe backwater in upstream of Gap. ${ }^{[1]}$ The width of the wide section is to $75 \mathrm{~m}$, while the canyon section part only about $10 \mathrm{~m}$. Moreover, the gradient of the riverbed changes severely. It is estimated that the height in wide section reduced to $36 \%$,the height in gorge reduced to $17 \%$. The U-shaped cross section of the river is formed in the long process of evolution. In the dry season, the water flow is small, due to the arc groove. While during the flood period, upstream of gap forms numerous backwater so that the upper bottomland and farmland are flooded. ${ }^{[2]}$

\section{RIVER CALCULATION MODEL AND BOUNDARY CONDITIONS}

Mathematical model is generalized by the actual river, with curved bottom surface and duplex trapezoidal cross section. The model is divided into 4 typical regions ,entrance section, wide section, gap and narrow section. The river is $206.5 \mathrm{~m}$ in length in total, and the maximum width of the river is $60 \mathrm{~m}$, the minimum is $11 \mathrm{~m}$. We carried out simulation respectively in four different conditions with the inlet flow of $35 \mathrm{~m}^{3} / \mathrm{s}, 55 \mathrm{~m}^{3} / \mathrm{s}, 75 \mathrm{~m}^{3} / \mathrm{s}$, $105 \mathrm{~m}^{3} / \mathrm{s}$.The generalized diagram of watercourse is shown in figure 1. 


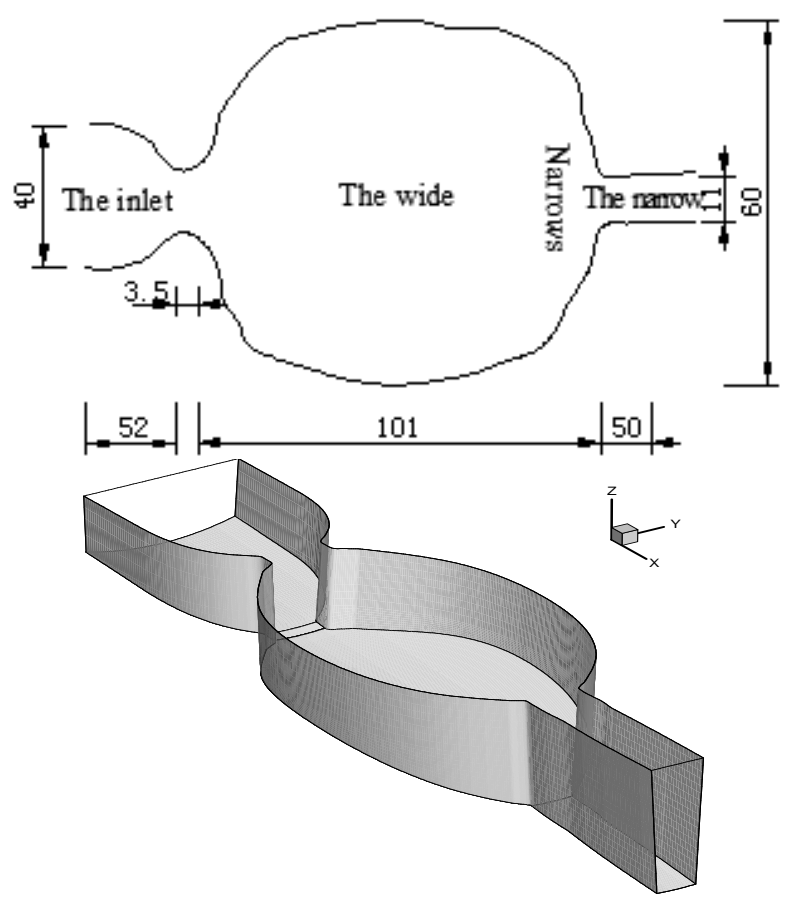

Figure 1.Generalized graph model(Unit: m)

First establish model into Gambit and mesh generation, then set up the boundary conditions: the lower part of the inlet is the flow inlet, the type is the velocity inlet boundary; the upper part is the air inlet, the type is pressure inlet boundary; the outlet is the one mixed with water and air, its type is pressure outlet boundary; ${ }^{[3]}$ the solid wall use the standard wall function method for treatment. The model uses FLUENT to do numerical simulation, and use the method of VOF, combining the standard $k-\varepsilon$ turbulence model coupled to calculate the flow field.

\section{THE RESULTS OF THE CALCULATION AND}

\section{ANALYSIS}

\section{A. The backwater range and influence}

Figure 2 is a schematic diagram about reflux area of 4 conditions. For condition 1,the flow is small and there is a small recirculation zone near the shore in upstream of Gap, but with no obvious backwater and about $30 \mathrm{~m}$ mainstream in width. In condition 2, the mainstream's width influenced by backflow is reduced from $36 \mathrm{~m}$ to $20 \mathrm{~m}$ in the range of $\mathrm{X}=116-153 \mathrm{~m} .{ }^{[4]}$ In condition 3 , the water spread to the entire wide section. Because of the shape of the recirculation regions, the width of the mainstream in the range of $X=100-135 m$ was not significantly decreased, only reduced from $40 \mathrm{~m}$ to $35 \mathrm{~m}$. In condition 4 , the recirculation zone expands to the scope of $\mathrm{X}=72-150 \mathrm{~m}$, and the width of the mainstream is reduced to $16 \mathrm{~m}$. From condition 1 to condition 4, the range of recirculation zone increases gradually, and there are apparent differences in the shape of the recirculation zones under different flow conditions.

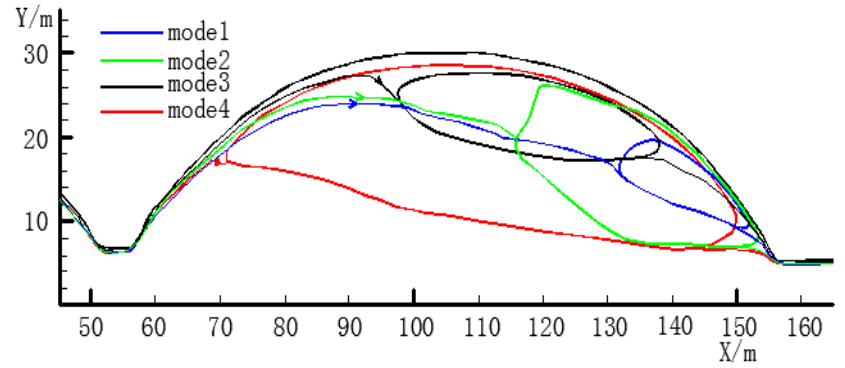

Figure 2.Schematic diagram about reflux area of 4 conditions

\section{B. Cross-sectional velocity distribution}

Figure 3, figure 4 are respectively the velocity contours of condition 1 and condition 3 at the cross section $X=120 \mathrm{~m}$. For condition 1 , because of the unobvious backwater, there is little influence on velocity distribution at the cross section $\mathrm{X}=120 \mathrm{~m}$. The maximum velocity zone is in the middle area of riverbed, with the size of $1.1 \mathrm{~m} / \mathrm{s}$. And the velocity decreases from the middle region to both sides.

Negative velocity region caused by reflux near the shore is small , at the range of $\mathrm{Y}=-12-12 \mathrm{~m}$, and the size of velocity changes significantly .For condition 3 , the maximum velocity is only $0.4 \mathrm{~m} / \mathrm{s}$, located on both sides of the axis at the cross section $X=120 \mathrm{~m}$. Due to the increased flow, and the backwater in upstream of gap rising violently, the mainstream is squeezed by reflux strongly, causing great differences in the cross-sectional velocity distribution compared with non-backwater section .Furthermore, negative flow rate region is bigger , accounting for $3 / 7$ of the entire cross section. Compared with condition 1, there are only small variations in velocity ,and the velocity distribution is more uniform in the range of $\mathrm{Y}=-12-12 \mathrm{~m}$.

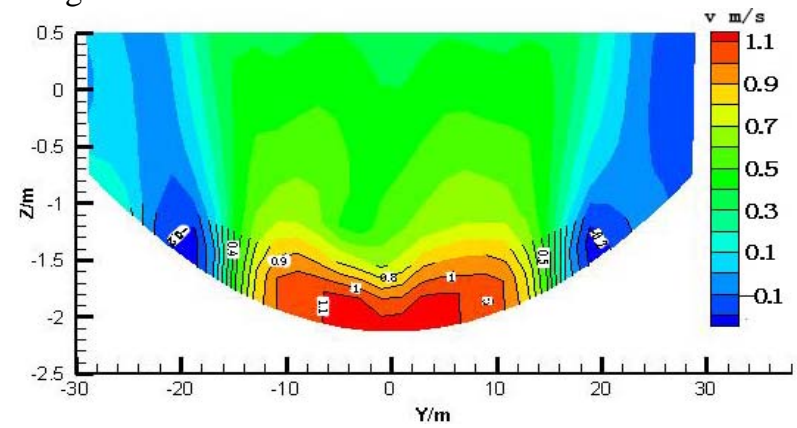

Figure 3.mode $1(\mathrm{X}=120 \mathrm{~m})$

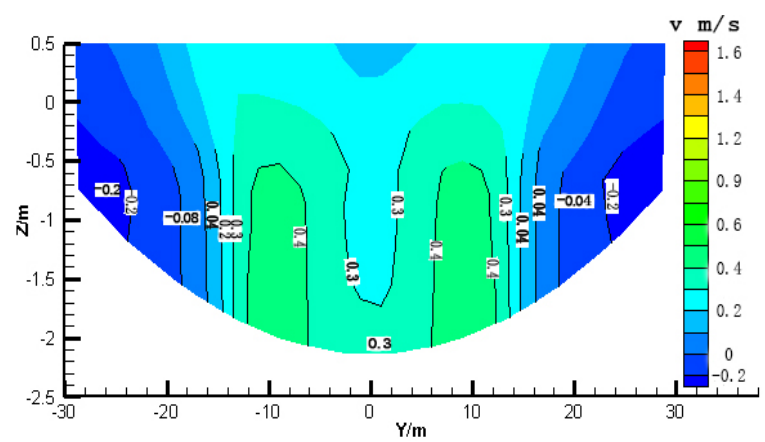

Figure 4.mode $3(\mathrm{X}=120 \mathrm{~m})$ 


\section{Cross-section bed shear stress distribution}

Figure 5 shows the cross-sectional bed shear stress distribution in four conditions at wide section $(X=120 \mathrm{~m})$. Since the mainstream is squeezed by reflux at different degrees, making the bed shear stress at wide sections distribute differently with different flow. Condition 1 and 2 at $\mathrm{X}=120 \mathrm{~m}$ is in the corresponding non-backwater zone, and the peak of the bed shear stress lies in middle section; With the flow increasing, the bed shear stress also increases. When the flow is further increased, the bed shear stress at first decreases and then increases at the middle region of wide sections. Condition 3 and 4 at $X=120 \mathrm{~m}$ is in the corresponding backwater zone, not only having less bed shear stress overall than conditions 1 and 2, but also the peaks are off and then back to the middle region under the influence of reflux.

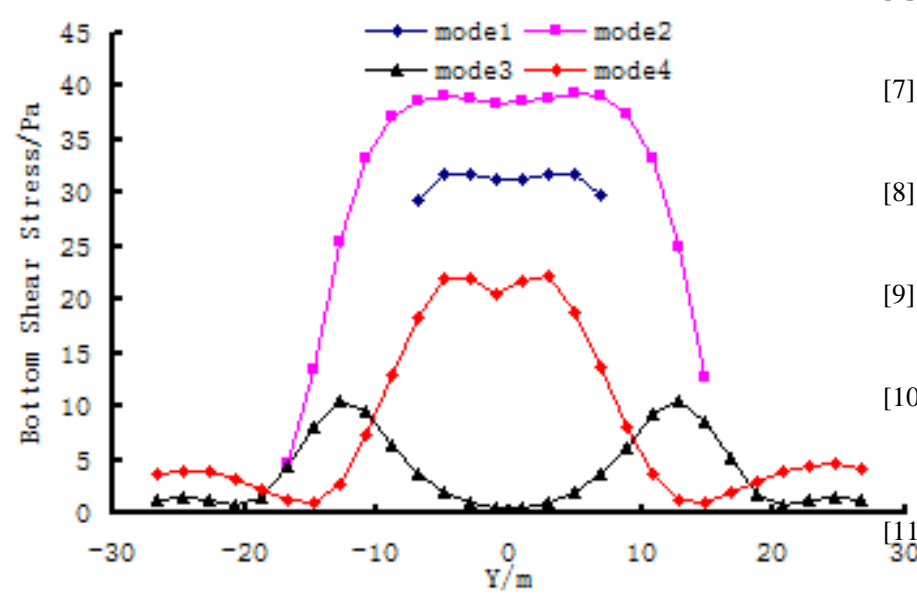

Figure 5.the cross-sectional bed shear stress distribution in four conditions at wide section $(X=120 \mathrm{~m})$

\section{CONCLUSION}

(1) Reflux often happens in the upstream of the gap. And as the flow increases, the area affected by the recirculation zone also increased. Under different flow conditions, there are apparent differences in the shape of the recirculation zone. (2) Reflux has great impact on the cross-section velocity distribution in the upstream of gap by pressing the mainstream channel. Moreover, the cross-section velocity distribution becomes more uniform with the increase of flow. (3) As the flow increases, the bed shear stress also increases in the section not affected by backwater, and the maximum is distributed in the central cross-section region. While the flow is further increased, under the influence of the reflux the bed shear stress in the central cross-section region at first decreases and then increases.

\section{ACKNOWLEDGMENT}

This work was supported by both Innovative Training Program and Interest Cultivation Program for Scientific Research in Sichuan Agricultural University.

\section{REFERENCES}

[1] Armellini A, Casarsa L, Giannattasio P. Separated flow struc-tures around a cylindrical obstacle in a narrow channel[J]. Experimental Thermal and Fluid Science, 2009, 33( 4) : 604- 619.

[2] PAIEMENT-PARADISG, MARQUISG, ROYA. Effects of turbulence onthe transport of individual particles as bedload in a gravel-bed river[J]. Earth Surface ProcessesandLandforms, 2011, 36( 1) : 107-116.

[3] LI Ai-xiang, SUN Yi, ZHAO Xiao-e, et al. Experi-mental Analysis and Numerical Simulation of U-shape Bend Flow $[\mathrm{J}]$. Journal of Yangtze River Scientific Re-search Institute, 2009, 26(9): 29 - 34. (in Chinese)

[4] YU Wen-chou, SU Chang-cheng. Forming Process of "Pocket-Shape"Caved Nest and Flow Structure in the Middle and Lower Reaches of Yangtze River $[\mathrm{J}]$. Yan-gtze River, 2007, 38( 8) : 156 - 159. (in Chinese)

[5] Nguyen Thanh Hoan, Rob Booij, Marcel J.F. Stive, et al, Decelerating open-channel flow in a gradual expansion[C]. Asian and Pacific Coast 2007, September 21-24, 2007, Nanjing, China: 902-915.

[6] Lucy C, Quine T A, Nicholas A. An experimental investiga-tion of autogenic behaviour during alluvial fan evolution[J]. Geomorphology, 2010, 115( 3 /4) : 278-285.

[7] Athanasios N. Papanicolaou, Robert Hilldale, Turbulence characteristics in gradual channel transition[J]. Journal of Engineering Mechanics, 2002, 128(9):948-960.

[8] Singha A, Balachandar R. Structure of wake of a sharp-edgedbluff body in a shallow channel flow $[\mathrm{J}]$. Journal of Fluidsand Structures, 2011, 27( 2) : 233-249.

[9] Wang Z Y ,Melching C S, Duan X H, et al. Ecological and hydraulic studies of step-pool system[J].Journal of Hydraulic Engineering,ASCE,2008,130(7):792-800.

[10] Grant G, Swanson F J, Wonlman M G. Pattern and origin of stepped-bed morphology in high-gradient streams, western Cascades,Oregon[J].Geological Society American Bulletin, 1990,102:340-352.

11] Aamarre H, Roy A G. The role of morphology on the displacement of particles in a step-pool river system[J] Geomorphology, 2008, 99: 270-279 .

[12] Montgomery D R, Buffington J M, Smith R D, et al. Pool spacing in forest channels [J].Water Resources Res, 1995,31:1097-1105.

[13] Chartrand S M, Whiting P J. Alluvial architecture in headwater streams with special emphasis on step-pool topography [J]. Earth Surface Processes and Landforms 2000,25:583-600.

[14] WU Chang-wen. Local Head Loss of Flow with HyperConcentration of Sediment in Sudden Expansion of Open Channel [J] . Sediment Re-search, 1989, (3): 82 - 89. (in Chinese)

[15] KUELEGAN G H. Laws of Turbulent Flow in Open Chan-nels $[\mathrm{J}]$. Journal of Research, U. S. National Bureau of Standards, 1938, 21: $701-741$.

[16] HU Jiang, YANG Sheng-fa. Study on Uniform Turbulence Structure in Smooth Open Channel [J]. Yellow River, 2009, 31( 3$): 23-25$. (in Chinese) 